
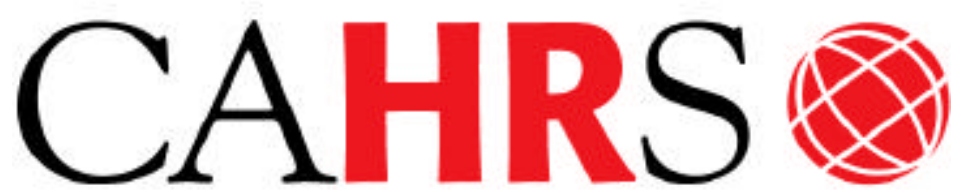

Center for Advanced Human Resource Studies
CAHRS / Cornell University 187 Ives Hall

Ithaca, NY 14853-3901 USA

Tel. 607 255-9358

www.ilr.cornell.edu/CAHRS/

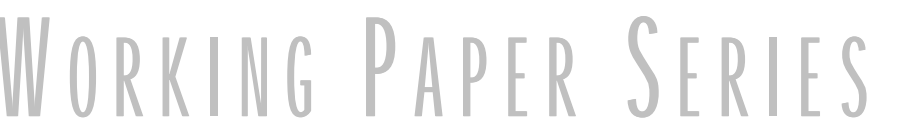

\section{The Transnational Challenge: Performance and Expatriate Presence in the Overseas Affiliates of Japanese MNCs}

\section{Schon Beechler \\ Vladimir Pucik \\ John Stephan \\ Nigel Campbell}

Working Paper 96-06 


\title{
The Transnational Challenge: Performance and Expatriate Presence in the Overseas Affiliates of Japanese MNCs
}

\author{
Schon Beechler \\ Columbia University \\ Graduate School of Business \\ 704 Uris Hall \\ New York, NY 10027 \\ tel: $212-854-4416$ \\ fax: 212-678-6958 \\ Vladimir Pucik \\ ILR School \\ Center for Advanced Human Resource Studies \\ Cornell University, Ithaca, NY \\ John Stephan \\ Columbia University \\ Graduate School of Business \\ Nigel Campbell \\ University of Manchester \\ Manchester, England
}

Working Paper \#96-06

Please address all correspondence to the first author.

Submitted to Strategic Management Journal, February 1996.

This paper has not undergone formal review or approval of the faculty of the ILR School. It is intended to make results of research, conferences, and projects available to others interested in human resource management in preliminary form to encourage discussion and suggestions. 


\title{
The Transnational Challenge: Performance and Expatriate Presence in the Overseas Affiliates of Japanese MNCs
}

\begin{abstract}
Drawing on empirical data from two studies of 119 Japanese affiliates located in the United States and Europe, this paper focuses on three fundamental questions: 1. What organizational factors influence performance of the overseas affiliates of Japanese MNCs? 2. What impact does expatriate staffing have on the affiliate's performance? and 3 . What factors influence expatriate staffing patterns in Japanese MNCs? While the empirical results lend some support to the assertion that MNCs characterized by global integration and local responsiveness will outperform less transnational competitors, there are significant differences between the American and European subsamples on the impact of expatriate presence on performance.
\end{abstract}




\section{Introduction}

Beginning with the pioneering work in international strategy of Bartlett and Ghoshal (1987; 1988; 1989), it has become accepted wisdom that the winners on today's global economic playing field will be those "transnational" firms which can simultaneously integrate their global operations and respond to local conditions, balancing the complementary and contradictory imperatives of organizational integration and differentiation (Lawrence and Lorsch, 1967; Evans and Doz 1989). While the organizational capability to simultaneously balance global integration and local responsiveness is seen as essential to implementing globally competitive strategies, this capability is not easily developed or sustained by multinational corporations (MNCs) (Bartlett and Ghoshal, 1989; Evans, 1993).

Although they have made rapid progress during the past decade, most observers agree that Japanese companies have had a particularly difficult time making the transition to transnational status (Bartlett and Yoshihara, 1989; DeNero, 1993; Kopp, 1994a). These arguments are consistent with a long held view that Japanese firms always lagged far behind their Western counterparts in their ability to manage international operations (e.g., Trevor, 1983; Kobayashi, 1985; Tachiki, 1991; Campbell and Holden, 1993), and with aggregate statistics showing relatively low profitability of Japanese investment abroad (MITI, 1994).

At the same time, there are a number of overseas success stories. Studies of Japanese affiliates have attempted to show that these companies are successful mostly because of factors associated with "exporting" Japanese management techniques, such as manufacturing techniques (e.g., Kujawa, 1986; Cusumano, 1988), quality control (e.g., Ebrahimpour and Cullen, 1993; Seko; 1994), training and development (Wakabayashi \& Graen, 1991) and careful socialization of local employees (e.g., Ouchi, 1981; Baliga and Jaeger, 1984).

However, as a number of authors have noted, while Japanese firms have been adept at creating systems to integrate their international operations globally, they have had a particularly difficult time in behaving in a locally-responsive way (Bartlett and Yoshihara, 1988; Fucini \& Fucini, 1990). The source of this difficulty has been identified as either Japanese MNCs' (JMNCs) unwillingness or their inability to recruit, retain and motivate capable local managers who have the expertise to adapt affiliate operations to the host country environment (DeNero, 1993).

Indeed, almost since they ventured overseas, academics, government officials and citizens from around the world have commented and criticized the large number of Japanese expatriates JMNCs employ in their overseas affiliates (Yoshino 1979; Sethi, Namiki \& Swanson, 1984). The "bamboo ceiling" (Boyacigiller, 1990a), or "rice paper ceiling" (Kopp, 1994b) has 
become synonymous with Japanese investment abroad. However, despite all the rhetoric, very little empirical work examining the management of Japanese firms overseas or their performance exists. Is there evidence that Japanese firms would benefit from greater localization to complement their relatively large degree of international integration? Is there evidence that they would benefit from a greater presence of local managers?

So far, most of the conclusions presented appear to be based on impressions and anecdotes, rather than systematic research. To begin to fill that gap, the studies reported in this paper were designed to shed more light on several key success factors that may influence the performance of Japanese multinational corporations.

In this paper we draw on several distinct research streams in the international management literature to address three basic questions: What organizational factors influence performance of the overseas affiliates of Japanese Multinational Corporations? What impact will Japanese expatriate staffing patterns have on the affiliate's performance and what factors influence expatriate presence?

While these three questions have been asked in isolation by previous researchers, in addressing these questions simultaneously, this study maps previously uncharted territory. It therefore represents a first step in developing a better understanding of what obviously is a very complex and dynamic phenomenon.

\section{Previous Research and Theoretical Framework}

In this paper we draw on two complementary approaches to propose a multilevel model of affiliate performance, linking the organizational control configurations embedded in Bartlett and Ghoshal's work in international competitive strategy (Bartlett and Ghoshal, 1987; 1989; 1992), with organizational demographic factors derived from the international life-cycle theory (Franko, 1973; Milliman et al., 1991) and the resource dependence framework (Pfeffer and Salancik, 1978; Aldrich, 1976).

\section{Predictors of Performance}

Porter (1986) suggested that industries can be roughly divided into multidomestic industries, in which firms compete against each other locally, uninfluenced by competitive dynamics in other countries, and global industries in which competition in one country influences or is influenced by competition in other parts of the world. Traditionally, much of Japanese manufacturing FDI was concentrated in global industries, such as electronics or automotive, driven primarily by export substitution strategies (Imai, 1993).

Beginning with Bartlett and Ghoshal (1987), a number of authors have suggested that firms competing in global industries which are able to develop the organizational capability to 
complement global integration with local responsiveness will be most successful (Taylor, 1991; Maljers, 1992), and this capability has been assessed from several theoretical perspectives (Egelhoff, 1993; Hennart, 1993; Hedlund, 1993). However, it is telling that the leading popular slogan of the transnational era, "Think globally, act locally," actually originated in Japan. While the dual imperatives of global integration and local responsiveness have been popularized at the corporate level, it is clear that operationally, they are local phenomena. Recent thinking in the strategy literature holds that it is imperative to look at strategies not at the firm level, but at a more micro level of analysis (Govindarajan and Gupta, 1985; Rosenzweig and Singh, 1991). Only a local affiliate can be simultaneously globally integrated and locally responsive (see also Gupta and Govindarajan, 1991; Milliman et al., 1991). Applying the logic put forth by Bartlett and Ghoshal (1987) to the affiliate level we hypothesize that:

$\mathrm{H1}$ : For MNCs operating in global industries, those affiliates which simultaneously exhibit high levels of integration with the rest of the parent firm and high levels of local responsiveness will have higher levels of performance than affiliates which have low levels of integration and/or responsiveness.

Affiliate performance can also be influenced by various demographic factors. Life-cycle theories (e.g., Franko, 1973; Milliman, et al., 1991) start with the premise that MNCs go through a predictable series of stages in their development. According to this school of thought, international experience and expertise are developed over time and thus, the age and experience of the firm are critical factors which are hypothesized to influence both the management and the performance outcomes in affiliates. Thus we may propose that affiliate age and the MNC's international experience can be thought of as organizational resources which should have a moderating and a positive impact on affiliate performance: H2a: The older the affiliate, the higher its level of performance.

$\mathrm{H} 2 \mathrm{~b}$ : The greater the MNC's experience in a host country, the higher the affiliate's level of performance.

Another important factor that may influence affiliate performance is the size of the organization. In general, the greater the size of the organization, the more organizational resources it has and the greater its ability to buffer its core from fluctuations in the external environment (Thompson, 1967). We would therefore predict that:

H3: Organizational size will be positively associated with affiliate performance. 
Finally, the affiliate's performance may also be influenced by the presence of expatriates from the home country of the MNC. In this paper, we build on the work of Boyacigiller (1990x; 1990b) and others to examine both the predictors and performance outcomes from the staffing policies in Japanese affiliates overseas. Is the assumption, often made but not tested, that the presence of Japanese expatriates promotes global integration but impedes local responsiveness correct? What impact, if any, does the presence of Japanese expatriates have on the performance of the affiliate?

The hypothesized relationship regarding the impact of expatriates on affiliate performance is not a straightforward one. On the one hand, the international human resource management literature describes a number of serious problems associated with expatriate-intensive staffing practices, including discontent, low morale, and high turnover among local managers (Zeira et al., 1975; Zeira, 1976; Pucik, et al., 1989; Bob and SRI, 1990; Kopp, 1994). On the other hand, too few expatriates can make it difficult for the parent firm to implement its global competitive strategies in an effective manner (Kobrin, 1988; Amako, 1991; Pucik, 1992).

From a theoretical perspective, while the life-cycle argument states that expatriates will be used under conditions of low performance, the subsequent impact of expatriate staffing on performance may itself be negative if, indeed, the use of expatriates is associated with lower levels of local responsiveness and lower levels of local responsiveness leads to lower levels of performance. At the same time, the international strategy literature postulates that in global industries, high levels of global integration, facilitated by a global network of mobile managers, is critical to MNC success.

Despite exhortations to the contrary, in most Japanese firms today, it is primarily expatriates who make up this international cadre of mobile managers. Therefore, the use of expatriates should increase the capability of the organization for global integration through a network of Japanese managers. At the same time, as noted by previous writers, the use of expatriates and the concomitant constraint on making full use of the talents of local managers may be the "Achilles Heel" of Japanese MNCS (Bartlett and Yoshihara, 1988), negatively influencing their adaptability to local conditions. As this stream of logic dominates the literature on the impact of expatriates on JMNC performance we propose, in spite of the caveats above, that:

$\mathrm{H} 4$ : The higher the ratio of expatriates to local nationals in the overseas affiliate the lower the affiliate's performance. 


\section{Predictors of Expatriate Presence}

If the presence of home country expatriates matters, what demographic variables identified above influence expatriate presence? Although most writers agree on the existence of expatriate-intensive (ethnocentric) staffing practices in Japanese MNCS (e.g., Kopp, 1994; Boyacigiller, 1990a; Trevor, 1983; Negandhi, 1979; Tung, 1982; Yoshino, 1976), there is considerable debate as to both the antecedents and the outcomes of these policies.

Following a life-cycle argument (Franko, 1973; Milliman et al., 1991), a number of authors have argued that expatriate-intensive staffing patterns in Japanese MNCs are due to the inexperience of Japanese firms overseas (e.g., Ichimura, 1981). Over time, the logic goes, Japanese companies, as they gain greater levels of experience abroad, will reduce the number of expatriates and "localize" their overseas operations (e.g., Ichimura, 1981; authors' interviews), just as American and European MNCs have done (Franko, 1973).

While this may have been a viable explanation in the 1970s and early 1980s, history has not supported this hypothesis. Japanese affiliates in the 1980s still used a relatively larger number of expatriates than their Western counterparts (e.g., Kopp, 1994). A number of authors, drawing primarily on small sample studies, have found that contrary to American, British and German MNCs, which gradually moved toward staffing policies that progressively limit expatriates, the Japanese still prefer to use those of their own nationality (Stening and Everett, 1984; Trevor 1983; Kopp, 1994).

Because the focus of almost all previous work has been on comparisons between Japanese and non-Japanese firms, the explanations offered for these results have generally been cultural. To these authors' knowledge, only one (unpublished) study has focused on inter-company comparisons between Japanese affiliates themselves. In the only study of its kind, Boyacigiller (1990a), conducted a study of staffing practices of Japanese affiliates in the United States in 1978 and 1988. She found that age of the affiliate was not related to the proportion of Japanese nationals in executive positions and on the board of directors in the affiliate and concluded that there is a bamboo ceiling in Japanese affiliates -- that Japanese MNCs do not tend to localize their affiliates by hiring more American nationals over time.

In addition to the cultural arguments, authors writing about MNCs in general have noted that firms have a tendency to use large numbers of expatriates during start-up (e.g., Franko, 1973) and when the MNC is in its early stages of internationalization (Perlmutter, 1969). This is due to the fact that early in their life cycle, MNCs are usually characterized by an ethnocentric culture (Perlmutter and Hennan, 1979) and their preoccupation is with short-term objectives 
(Adler and Ghadar, 1989; Dowling and Schuler, 1990; Milliman, et al, 1991). These considerations lead us to predict that:

H5a: The younger the affiliate, the more expatriates will be used to staff affiliate positions.

$\mathrm{H} 5 \mathrm{~b}$ : The fewer the number of years of experience of the parent company in the host country, the more expatriates will be used to staff affiliate positions.

Although age and international experience should decrease the reliance on expatriates to staff overseas affiliate positions, there are a number of countervailing forces which may lead MNCs to use a larger number of expatriates in their overseas affiliates. Drawing again on the arguments of Bartlett and Ghoshal (e.g., 1989), expatriates should increase the capability of the organization to integrate its operations globally since these human resources generally form an international cadre which functions as a critical linking mechanism across interdependent subunits within the MNC (Edstrom and Galbraith, 1976).

In addition, expatriates can be thought of as a mechanism of organizational control (Edstrom and Galbraith, 1976; Boyacigiller, 1990b; Beechler, 1992). Following a resource dependence argument (Aldrich, 1976; Salancik and Pfeffer, 1978), the more the MNC depends on an affiliate, the higher its need to control that affiliate. Although large affiliates will tend to have more power than small affiliates vis a vis their parent companies because they control a larger pool of resources (Doz and Prahalad, 1981), large affiliates will also be subjected to greater degrees of control by the parent. Staffing key affiliate positions with expatriates may be one way to exercise control over the affiliate, especially in Japanese MNC's where socialization of local managers has proven to be difficult (Pucik, 1994; Kopp 1994). We therefore predict that:

H6: The larger the affiliate, the greater the use of expatriates in the overseas affiliate. In a similar pattern, higher levels of integration between affiliate and parent company operations should also lead to the need for higher levels of coordination and control, thus increasing the need for expatriates. We therefore predict that:

$\mathrm{H7}$ : The more the operations of the affiliate are integrated with those of the parent, the greater the use of expatriates in the overseas affiliate.

Turning to level of localization, no specific predictions are made. On the one hand, the more functions are localized, the greater the ability of the firm to attract qualified local managers. If qualified local managers are present, this reduces the pressure on the MNC to staff its affiliate with expatriates. At the same time, however, a greater number of functions 
present in the affiliate may increase the strategic importance of the affiliate to the parent, increasing the dependence of the parent company on the affiliate, and hence, the need for control. This need for control may, in turn, increase the use of expatriates in the affiliate. Finally, we would expect that in those affiliates which are simultaneously globally integrated and locally differentiated, we would find control demands at their highest and the greatest need for a large percentage of expatriates to manage the contradictory and complex demands placed on the affiliate. We would similarly expect that those affiliates with low levels of integration and high levels of localization will have the lowest levels of expatriate staffing. We can summarize these predictions in the following hypotheses:

H8a: Affiliates with simultaneously high levels of integration and localization will have the highest levels of expatriate staffing.

H8b: Affiliates with low levels of integration and high levels of localization will have the lowest levels of expatriate staffing.

\section{Methodology}

The results in this paper are based on data collected from 119 Japanese affiliates in two parallel studies of management practices and outcomes in Japanese affiliates overseas, the first conducted in the United States in 1989 and the second in Europe in 1992. In the U.S. study, the sample was drawn from a non-random stratified sample of 41 affiliates of the 32 largest Japanese owned firms concentrated in high-tech industries, consumer electronics, automotive manufacturing, and finance and services. With only minor exceptions, all major Japanese investors in the United States (Toyo Keizai, 1989) were represented in the sample and all were competing in globally competitive environments.

First, confidential interviews were conducted with two to three members of top management in each company. Then, questionnaires were given to the managers who were also requested to distribute additional written questionnaires to their peers. Questionnaire responses were received from three to eight local executives in each company.

Sixty-two of the 132 distributed questionnaires were completed for a response rate of $61 \%$. Because there are multiple responses from the U.S. affiliates in the study, the data have been inversely weighted by the number of respondents to counteract the impact of unmeasured company influences on the results reported in this paper.

While the empirical results reported later in this paper are based on the responses to the written questionnaires, we are able to interpret these results with the knowledge and insights gained in 51 interviews with local executives, Japanese executives stationed at the affiliates, 
Japanese executives in charge of international operations in the Japanese headquarters, and local executives who had been previously employed in Japanese affiliates.

The European study was conducted in 1992 as a follow-up to the American study in order in test whether the relationships found in the American data were consistent across host countries. Because of high levels of convergent validity found in the responses of same-affiliate respondents in the American data, in the European study questionnaires were sent only to the top local executive in each affiliate in the sample. Of the 175 questionnaires distributed to the largest affiliates of Japanese firms in Europe, 78 usable responses were received for a response rate of $45 \%$. The final European sample consists of 44 U.K. affiliates, 26 German, 6 French, 3 German, and 3 unidentified European affiliates.

\section{The Variables Used in the Study}

Descriptive statistics and correlations for all of the variables used in the analyses are presented in Tables 1 and 2 below.

\section{TABLE 1}

\section{DESCRIPTIVE STATISTICS}

\begin{tabular}{|c|c|c|c|c|c|c|c|c|c|}
\hline \multirow[t]{2}{*}{ Variable Name } & \multicolumn{3}{|c|}{ Whole Sample } & \multicolumn{3}{|c|}{ U.S. Subsample } & \multicolumn{3}{|c|}{ European Subsample } \\
\hline & Mean & Std. Dev. & Range & Mean & Std. Dev. & Range & Mean & Std. Dev. & Range \\
\hline$\%$ Expatriates in Affiliate & 0.077 & 0.096 & $0-.6$ & 0.096 & 0.118 & $0-.6$ & 0.067 & 0.082 & $0-.50$ \\
\hline Performance (Profit Level) & 2.758 & 1.036 & $1-5$ & 2.591 & 1.077 & $1-5$ & 2.849 & 1.009 & $1-5$ \\
\hline Affiliate Age $\mathrm{e}^{\star \star \star}$ & 13.918 & 8.561 & $2-39$ & 18.953 & 9.762 & $7-39$ & 11.233 & 6.456 & $2-31$ \\
\hline Parent Experience in Host ${ }^{\star \star *}$ & 19.778 & 10.066 & $4-46$ & 24.035 & 10.096 & $7-40$ & 17.092 & 9.143 & $4-46$ \\
\hline Affiliate Sizet & 465.694 & 831.496 & $5-6000$ & 689.234 & 1152.078 & $5-6000$ & 352.433 & 586.615 & $14-3500$ \\
\hline Average Integration"** & 2.210 & 0.582 & $1.08-4$ & 2.022 & 0.474 & $1.33-3.42$ & 22.312 & 0.612 & $1.083-4$ \\
\hline Localized Functions & 10.202 & 2.635 & $0-12$ & 0.366 & 2.517 & $0-12$ & 10.115 & 2.706 & $0-12$ \\
\hline Manufacturing Parent* & 0.790 & 0.410 & $0-1$ & 0.659 & 0.480 & $0-1$ & 0.859 & 0.350 & $0-1$ \\
\hline Manufacturing Affiliate ${ }^{\star \star}$ & 0.445 & 0.499 & $0-1$ & 0.244 & 0.435 & $0-1$ & 0.551 & 0.501 & $0-1$ \\
\hline
\end{tabular}

Notes:

Significance levels for differences in means between U.S. and European subsamples and correlation coefficients:

$\mathbf{t}=p<.10 ; *=p<.05 ; * *=p<.01 ; * * *=p<.001$

Ns: Whole Sample $=119$; U.S. Subsample $=41$; European Subsample $=78$ 
TABLE 2

\section{CORRELATION TABLE}

\section{Variable Name}

1) \% Expatriates in Affiliate

2) Performance (Profit Level)

3) Affiliate Age

4) Parent Experience in Host

5) Affiliate Size

6) Average Integration

7) Localized Functions

8) Manufacturing Parent

9) Manufacturing Affiliate
123

\section{4}

5

6

7

8 $-.013$

.114

$.021-.071$

$\begin{array}{llll}-.223^{*} & .117 & .098 & .105\end{array}$

$\begin{array}{lllll}.017 & .154 & .070 & -.014 & -.075\end{array}$

$\begin{array}{lllll}-.169 t & .064 & .003 & .035 & .080\end{array}$

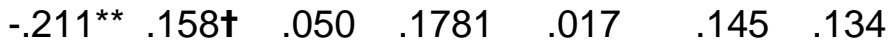

$\begin{array}{llllll}-.280^{* *}-.166 \dagger & -.426^{* *}-.269^{* *} .213^{*} & -.044 & .118 & .089\end{array}$

Notes:

Significance levels for differences in means between U.S. and European subsamples and correlation coefficients:

$$
\mathbf{t}=\mathrm{p}<.10 ;^{*}=\mathrm{p}<.05 ;^{* *}=\mathrm{p}<.01 ;^{* * *}=\mathrm{p}<.001
$$

Ns: Whole Sample $=119 ;$ U.S. Subsample $=41$; European Subsample $=78$

\section{Dependent Variables}

Affiliate Performance. Measuring the performance of Japanese affiliates is extremely difficult for two critical reasons: Japanese accounting laws do not require separate reporting for individual affiliates of Japanese companies so there are no publicly available figures and affiliate performance figures are considered to be confidential and proprietary data. Furthermore, even when companies will divulge the performance data, financial performance figures at the affiliate level are notoriously unreliable since such inputs as internal transfer prices are manipulated for taxation and other reasons (Rosenzweig, 1994). Although all measures of performance are biased, we chose to measure performance through self-reported ratings of the affiliate's performance. Previous research has found strong correlations between objective and subjective performance ratings (Dess and Robinson, 1984; Geringer and Hebert, 1991) and since all respondents are top level executives in the affiliate with knowledge of the affiliate's true performance and because they were guaranteed anonymity, these self-report measures are likely to be more accurate than other numerical figures such as profitability, ROL etc.

In the questionnaire, we asked a number of questions about various dimensions of affiliate performance, using Likert-type scales to indicate level of affiliate performance. In the analyses reported below, we used the respondent's rating of their affiliate's current overall level of profitability vis a vis the performance of their top competitor. 
Expatriate Presence. Expatriate presence was measured by taking the percentage of expatriates currently stationed in the affiliate to all affiliate employees. Independent and Control Variables

Integration between the affiliate and the parent company was measured by creating an averaged index of integration across the functional areas of operations, procurement, marketing, sales, distribution, business planning, accounting, legal affairs, product development, research and development, and human resource management. In all cases respondents were asked to indicate on a Likert-type scale how integrated each of these functions were between the affiliate and the parent company. For those affiliates where particular functional areas were not relevant to the business of the affiliate (e.g., manufacturing functions for service affiliates) the index was adjusted accordingly. Higher values on the index indicate higher levels of integration between the affiliate and the parent company.

Degree of local responsiveness was measured by proxy by an additive index of all the major value-chain functions actually performed at the affiliate. We used this measure of the affiliate's organizational configuration to represent the extent of the affiliate's interface with the local environment and hence its degree of local responsiveness.

Age of the affiliate was determined by subtracting the year of the affiliate's founding from 1993.

Size was measured by the actual number of employees working in the affiliate.

Parent company's experience in the host country was measured by the number of years since the company first established operations in the host country.

Whether the parent is a manufacturing firm or not and whether the affiliate has manufacturing operations were coded as dummy variables where the variable had a value of 1 if the parent/ affiliate was engaged in manufacturing.

\section{Results}

\section{Description of Respondents}

Most participating companies are among the largest industrial, financial and service firms in Japan. The majority of them are market leaders in their lines of business, with total worldwide sales ranging from $\$ 600$ million to $\$ 45$ billion and a global workforce of between 2200 to 163,000 employees, with a mean of 38,400 employees worldwide.

Fifteen percent of respondents hold the top position in their affiliate and an additional $42 \%$ of respondents reported to the president or general manager of the affiliate. The remaining respondents hold other executive positions in the affiliate. Respondents have been with their 
company for an average of 9.18 years, with a range of service from 2 to 25 years. Nearly all respondents (114 of the 119 respondents) are male.

\section{Subsample Descriptive Statistics}

The affiliates included in the sample are, on average, well-established in their host country. For the American affiliates, the average age of the affiliates is 19 years old and parent companies had, on average, 24 years of experience in the United States (see Table 1). In the European subsample, the average age of the affiliate is I 1 years old and parent companies have an average of 17 years of experience in the host country (see Table 1).

In terms of size, American affiliates have, on average, 689 employees while the European affiliates are smaller, with 352 employees. $66 \%$ of the American affiliates and $86 \%$ of the European affiliates have manufacturing parent firms while $24 \%$ of the American affiliates and $55 \%$ of the European affiliates themselves have manufacturing operations.

There are some significant differences between the U.S. and European affiliates. Using difference in means tests between the two subsamples, we find that American affiliates are significantly older $(p<001)$ than their European counterparts. Similarly, the parent companies of the U.S. sample have significantly longer experience in the host country (significant at $\mathrm{p}<001$ ). In addition, the average number of employees in the U.S. affiliates is somewhat larger than in the European affiliates (significant at $p<1$ ).

Integration between the parent company and the affiliate also differs significantly between the two subsamples. European affiliates are, on average, more integrated with their parent companies than U.S. affiliates (mean=2.31 versus $2.02 ; \mathrm{p}<01$ ). In terms of localization of functions to the affiliate, there is virtually no difference between the American and European subsamples (mean for U.S.=10.37 vs. Europe=10.12). In addition, the rank order correlation (see Table 2) between integration and localization for the sample as a whole is quite low and negative (0.0528). However, in the American subsample, the correlation is positive and moderate $(0.2560)$ while in the European subsample, the correlation is negative and moderate $(-0.2523)$.

The U.S. and European subsamples do differ significantly on the extent to which both the subsidiary and the parent are engaged in manufacturing activities. At the subsidiary level, there is a higher percentage of manufacturers in the European subsample than in the U.S. sample (mean=.55 vs. mean=.24; $p<.01 ;$ ). At the parent company level, the European subsample also has a higher percentage of firms engaged in manufacturing than the U.S. subsample (mean=.86 versus $.66 ; \mathrm{p}<05)$. 


\section{Multivariate Analyses: Analysis of Performance}

For all of the regression analyses Ordinary Least Squares models were built in a hierarchical fashion. We first entered the variables of affiliate age, parent company experience in the host country, and affiliate size. Then, in a second step we added the quadratic measure of affiliate size to test for nonlinearity. While we do not report the results here, the addition of the size-squared variable significantly increased the adjusted R-square statistic in each equation.

Using the profitability of the affiliate vis a vis its competitors as the measure of performance, we first performed a regression analysis using the total sample of Japanese affiliates located in the United States and Europe. These results are presented in Table 2 below. As shown in the table, for the whole sample, profit is a function of subsidiary size, level of integration with the parent company, and localization of affiliate functions (Adjusted R-square=.15; $p<01)$.

Size shows a significant quadratic relationship with profitability. In small to medium sized affiliates, increasing size is associated with decreasing performance $(p<1)$. This relationship reverses once affiliate size increases beyond a certain point and size then shows a positive relationship to profitability $(p<01)$. While the results are more complex than hypothesized, these results offer partial support for Hypothesis 3 which predicted that size would be positively associated with affiliate performance.

Affiliates with higher levels of integration with the parent also report significantly higher levels of performance than do affiliates with lower levels of integration $(p<01)$. In addition, affiliates with a greater number of localized functions outperform their counterparts with fewer localized functions $(p<1)$. Hypothesis 4 is therefore supported.

The age of the affiliate, parent company's experience in the U.S., the percentage of expatriates in the affiliate, and the control variables for whether the parent company is a manufacturing firm and whether the affiliate has manufacturing operations are all nonsignificant predictors of affiliate performance. These results do not support Hypothesis 1 or Hypothesis 2 which predicted that both affiliate age and parent company experience would be associated with higher levels of affiliate performance.

To explore whether these results are consistent across Japanese affiliates in both the United States and Europe, we next performed identical analyses on each subsample separately. These results are also presented below in Table 3. 


\section{TABLE 3}

\section{REGRESSION RESULTS FOR AFFILIATE PROFITABILITY}

Independent Variable
Intercept
Affiliate Age
Parent Experience in Host
Affiliate Size
Affiliate Size
Expatriate Presence
Average Integration
Localized Functions
Manufacturing Parent
Manufacturing Affiliate
R$^{2} / \mathrm{F}(\mathrm{df})$

\section{Whole Sample \\ Beta S.E.}

$\begin{array}{ll}1.217 \boldsymbol{t} & 0.6820 \\ 0.001 & 0.0163 \\ -0.0078 & 0.0139 \\ -0.0005 t & 0.0031 \\ 0.000002 \bullet \bullet 0.0000 \\ -0.7276 & 1.103 \\ 0.5065 \bullet \bullet & 0.1727 \\ 0.0893 \boldsymbol{t} & 0.0479 \\ 0.063 & 0.2598 \\ -0.4226 \boldsymbol{t} & 0.2373 \\ .15 / \mathrm{F}=2.852(9,96) \bullet \bullet\end{array}$

\section{U.S. Subsample European Subsample Beta S.E. Beta S.E.}

$\begin{array}{ll}-1.819 \dagger & 0.9267 \\ 0.0123 & 0.0201 \\ 0.0277 & 0.0185 \\ -0.00025 & 0.00047 \\ 1.3^{*} 10^{-7} & 8.0 \star 10^{-8} \\ 1.7470 & 1.4536 \\ 1.2869 \bullet \bullet \bullet & 0.3096 \\ 0.1184 \boldsymbol{t} & 0.0623 \\ -0.5570 & 0.4261 \\ -0.0260 & 0.4190 \\ .46 / \mathrm{F}=4.395(9,36) \bullet \bullet\end{array}$

$\begin{array}{cl}2.064 \bullet & 1.007 \\ 0.0151 & 0.0250 \\ -0.0284 & 0.0182 \\ -0.00121 & 0.0006 \\ 3.8^{*} 10^{-7} \boldsymbol{\dagger} & 2.0^{*} 10^{-7} \\ -2.9911 & 1.6285 \\ 0.2547 & 0.2156 \\ 0.1110 & 0.0689 \\ 0.1621 & 0.3576 \\ -0.5585 \boldsymbol{t} & 0.3033 \\ .13 / \mathrm{F}=1.980(9,59) \mathbf{t}\end{array}$

As shown in the table, controlling for presence of manufacturing at the affiliate and the parent, the only significant predictors of affiliate performance in the U.S. sample are integration and localization (Adjusted R-square=.46; $p<01$. Higher levels of integration between the parent firm and the affiliate are associated with significantly higher levels of affiliate performance $(p<.001)$ and a larger number of localized functions is associated with significantly higher levels of performance $(p<.1)$. These results support Hypothesis 4.

In addition, in the U.S. sample there is no significant relationship between expatriate presence and affiliate performance. However, contrary to the results for the total sample, size is not an important predictor of performance for the U.S. subsample, although the nature of the relationship is consistent with that found in the total sample analysis.

In the European subsample (see Table 3), size of the affiliate, expatriate presence, and whether the affiliate is engaged in manufacturing significantly predict affiliate performance (Adjusted R-square=.13; $p<1$ ). Consistent with the previous analyses, size exhibits a quadratic effect with performance $(p<1)$. In small to medium sized affiliates, increasing size is associated with decreasing performance. This relationship reverses once affiliate size increases beyond a certain point and then increasing size is associated with increased performance.

In the European subsample, an increase in the percentage of expatriates is significantly negatively related to performance $(p<1)$. Finally, European affiliates with manufacturing operations have significantly lower levels of performance than affiliates with no manufacturing $(p<1)$ and parent company-affiliate integration and localization of functions have no significant influence on affiliate performance, contrary to our prediction in Hypothesis 4. 


\section{Interpretation of Performance Results}

Examining the results for affiliate performance, the results of the analyses reported above for the whole sample lend support to Bartlett and Ghoshal's assertion that MNCs with both a high level of integration and a high level of local responsiveness will outperform their less transnational competitors. While we do not include the analyses below, we also tested for an interaction effect between integration and local responsiveness on the level of affiliate performance. In neither the sample as a whole nor in the two subsamples was this term significant, however.

In addition, we examined the data to see whether the relationships between integration and performance and localization and performance were consistent across the range of variable values or whether there are "ideal levels" of integration and/or localization. Examining the scatter plots for each of these variables plotted against performance shows no such "ideal point." The data do indicate that to benefit from a transnational organizational strategy, a certain degree of maturity of the affiliate may be required. This may explain why the two configuration variables are so important in the U.S. case (the two variables alone account for $41 \%$ of the explained variance in performance), but are not significant in the European sample. This observation fits with the proposition advanced by Rosenzweig (1994) that the critical nature of the American market requires an asymmetric approach to managing affiliates. This, at least in our sample of Japanese MNCs, is clearly the case.

Another possible explanation for the low impact of "transnational" variables on performance in the European sample may be due to the presence of "overintegration" between the affiliates and the parent companies. On average, Japanese affiliates in Europe are more integrated with their parent firms than are their American counterparts (see Table 1). Although we cannot determine causality from these data, high integration may lead to high levels of expatriate presence, which in the European context, shows a negative association with performance. In the U.S., on the other hand, expatriate presence shows no significant relationship with affiliate performance, although it is worth noting that the coefficient is positive. In fact, in a preliminary analysis of the data not reported here, the expatriate variable was both positive and significant for the U.S. subsample, although its significance dropped with the addition of the parent company dummy variable to the final model.

The impact of expatriate presence on performance clearly requires further study as the direction of the relationship is opposite for the two subsamples. It is also possible that the critical variable may not be only the expatriate presence per se, but also the role and quality of individual expatriates assigned to the subsidiaries. Based on the interviews with top level 
executives in the affiliates, we observed that Japanese expatriates in the U.S. are more frequently found in "hadow" integrating roles, managing a global web of relationships, while their counterparts in Europe are more heavily involved in day-to-day control of affiliate operations.

Some of the differences between the U.S. and European samples can be attributed to differences in the age of the affiliate and/or experience of the parent company in the host country. However, in our regression models, none of the life-cycle variables are significant predictors of performance. More experience does not lead to higher performance. To the contrary, in the case of European affiliates, the relationship is negative -- greater levels of experience are associated with lower levels of affiliate performance.

The differences found between the American and European subsamples also indicate that the assumption of a simple linear learning curve positively enhancing the performance of overseas operations may be an oversimplification. It may be that the organization's ability to learn from the local environment is not merely linked to experience, but to other, unmeasured organizational factors as well.

Turning to the relationship between size and affiliate performance, the non-linearity of the relationship is striking. There are several explanations of why medium-size affiliates may show the lowest levels of performance. First, their growth may have outpaced the available resource support from the parent company. This could be the case in Europe, which is often ranked third in priority by Japanese MNCs, after Asia and the United States. Also, we found from company visits that there were several instances where European affiliates were in the process of making a difficult and painful transition from basically an entrepreneurial mode to one of a mature business. With these changes often came changes in local management, with a correspondingly negative effect on organizational stability, employee morale, and customer relations.

Multivariate Analysis: Analysis of Expatriate Presence

To further explore the issue of expatriate presence, we conducted an additional set of analyses using percentage expatriates to total number of affiliate employees as the dependent variable. These results are shown in Table 4 below. 
TABLE 4

REGRESSION RESULTS FOR EXPATRIATE PRESENCE IN AFFILIATE

\section{Independent Variable}

Intercept

Affiliate Age

Parent Experience in Host

Affiliate Size

Affiliate Size

Average Integration

Localized Functions

Manufacturing Parent

Manufacturing Affiliate

$\mathrm{R}^{2} / \mathrm{F}(\mathrm{df})$

\section{Whole Sample \\ Beta S.E.}

$\begin{array}{ll}0.1304 \bullet & 0.6410 \\ 0.0010 & 0.0013 \\ 0.00002 & 0.0013 \\ -0.00008 \bullet \bullet & 0.00003 \\ 1.35 * 10^{-8} & 1.0^{*} 10^{-8} \\ 0.0152 & 0.0165 \\ -0.0014 & 0.0046 \\ -0.0643 \bullet \bullet & 0.0238 \\ -0.0230 & 0.0227 \\ .17 / F=3.457(8,97) \bullet \bullet\end{array}$

\section{U.S. Subsample European Subsample Beta S.E. \\ Beta S.E.}

$\begin{array}{ll}0.219 \dagger & 0.111 \\ -0.0001 & 0.0025 \\ 0.0047 & 0.0023 \\ -0.00012 \bullet & 0.00005 \\ 1.91 * 10^{-8}{ }^{\dagger} & 1.0^{*} 10^{-8} \\ 0.0166 & 0.0394 \\ -0.0044 & 0.0079 \\ -0.1207 \bullet & 0.0477 \\ 0.0277 & 0.0518 \\ .26 / F=2.632(8,37)\end{array}$

$\begin{array}{ll}0.0620 & 0.0862 \\ 0.0030 & 0.0021 \\ -0.00015 & 0.0016 \\ -0.00013 \bullet & 0.00005 \\ 3.18^{*} 10^{-8^{\dagger}} & 2.0^{*} 10^{-7} \\ 0.0286 & 0.0181 \\ 0.0055 & 0.0059 \\ 0.0042 & 0.0307 \\ -0.00012 & 0.0261 \\ .14 / F=2.245(8,59)\end{array}$

NOTE: $\boldsymbol{t}=p<.10^{*}=p<.05^{\star *}=p<.01^{\star \star *}=p<.001$

For the total sample, we find that the level of expatriate staffing is significantly influenced only by size of the affiliate and whether the parent firm is a manufacturer (Adjusted R-square =.17; $\mathrm{p}<.005)$.

Hypothesis 7 is partially supported as size exhibits a non-linear, U-shaped effect on expatriate presence $(p<05)$. As size increases from small to medium, the percentage of expatriates declines. However, when size increases past a certain point, expatriate presence begins to increase with increasing size.

There is no significant relationship between number of localized functions and expatriate presence and affiliates of manufacturing parent firms have lower percentages of expatriates in their affiliates than do non-manufacturers $(\mathrm{p}<01)$. Affiliate age, the presence of manufacturing operations at the affiliate, experience of the parent company in the host country, and integration between the affiliate and the parent company are all non-significant predictors of expatriate presence. Hypotheses 5a, 5b, 6 and 7 are therefore not supported.

For the U.S. subsample (see Table 3), the results are identical but stronger than those for the entire sample (Adjusted R-square=.25; $p<05$ ). The parent company's experience in the United States, age of the affiliate, the presence of manufacturing at the affiliate, integration between the parent company and the affiliate, and localization of functions at the affiliate, are all non-significant predictors of expatriate presence in the U.S. subsample. 
For the European affiliates, expatriate presence is significantly predicted only by size (Adjusted R-square=.14; $p<05$ ), which again shows a quadratic effect with expatriate presence. All of the other variables are non-significant.

Finally, we also tested for an interaction effect between integration and local responsiveness on the level of expatriate staffing, controlling for all other variables included in the regression equations above. While we do not include the analyses below, in neither the sample as a whole nor in the two subsamples was this term significant.

While the regressions are not significant, we did find significant interaction effects when we split the variables into "high" and "low" at either the mean or median on level of localization and level of integration and performed an ANOVA, controlling for all of the other variables included in the regression equations above. As shown in Table 5 below, we find that after entering the control variables, those affiliates which have simultaneously high levels of localization and high levels of integration have the greater percentage of expatriates $(r=.111)$, as predicted in Hypothesis 8a. Also, as predicted in Hypothesis 8b, the lowest percentage of expatriates is found in those affiliates which are low on integration and high on localization $(i=.050)$.

\section{TABLE 5}

ANOVA RESULTS OF INTEGRATION AND LOCALIZATION ON EXPATRIATE

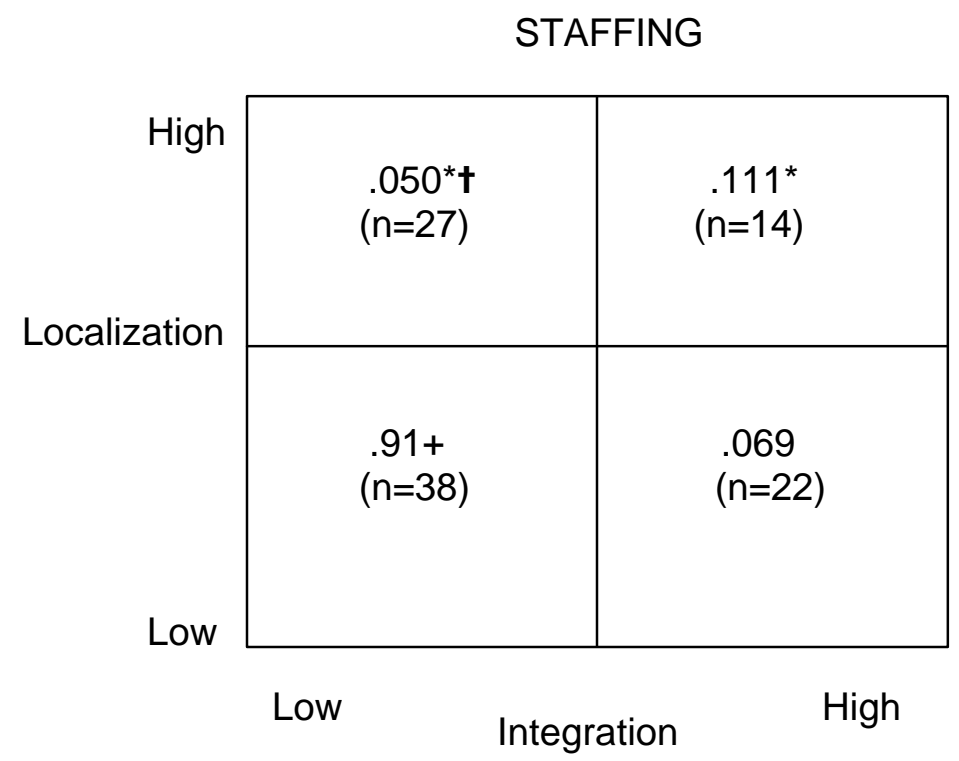

Overall $F=3.57$

Interaction $=p<.03$

- $\quad$ significant difference, $p<.05$

+ significant difference, $p<.10$ 


\section{Interpretation of Expatriate Presence Results}

Examining the predictors for expatriate staffing, the results of the analyses provide no support for the life cycle predictions that age of the affiliate and parent company experience in the host country will reduce the affiliate's reliance on expatriates. These results are, however, consistent with Boyacigiller's (1990a) findings in the U.S. that age of the affiliate was unrelated to Japanese MNCs' use of expatriates.

At the same time, integration with the parent company does not predict expatriate presence, contrary to our hypothesis based on the resource dependence framework. While we had originally predicted that the need for greater levels of parent company control over integrated affiliates would be reflected in an increase in expatriate presence, the parent companies may be using other forms of control (e.g., bureaucratic rules and procedures, socialization of local employees, direct communications and visits from the parent company, etc.) to manage this interdependence. Although integration along does not lead to greater levels of expatriate staffing, the results presented in Table 4 above do support a resource dependence prediction that simultaneously high levels of integration and localization will lead to the highest level of expatriate staffing. Clearly these relationships deserve further study.

The analyses also show that expatriate presence is influenced by size of the affiliate for both the U.S. and European affiliates. The results indicate that larger affiliates have the greatest expatriate presence while medium-sized affiliates have the smallest expatriate presence. While our results do not support traditional life-cycle theory predictions, they do support a modified life-cycle argument where, instead of time in the host country, scope of operations is a critical factor in determining expatriate presence. As other authors have indicated (e.g., Franko, 19?3) expatriates may be sent upon start-up of a new operation and then replaced once the operation is up and running. However, once the operation reaches a certain size, expatriates are again stationed in the affiliate, independent of the age of the affiliate, the parent's experience in the host country, the level of integration between the affiliate and the parent company, or the localization of functions to the affiliate.

\section{Discussion}

Given the fundamentally exploratory nature of the study, a number of observations made here are still tentative and require further clarification and refinement. While our ability to collect two independent sets of data from two distinct populations of Japanese affiliates allows us to present a number of previously untested propositions, the complexity of many of the underlying relationships also becomes more obvious. Therefore, additional research is needed to validate and extend the current findings and two areas in particular should receive close attention. 
With respect to several of the organizational-level variables, such as global integration and local responsiveness, it may be useful to confirm their predictive power by using alternative, more detailed measures than were available in this study. Finer differentiation by industrial sectors may also be appropriate, as the benefits of transnational strategies are influenced by the sources of competitive advantage and the nature of competition in the industry.

Because of the cross-sectional nature of our data, we are unable to infer causality between the variables examined in this study. It may be that size is associated with affiliate performance not because availability of resources improves competitive capabilities, but because successful affiliates simply grow faster than less successful ones. In addition, expatriates may hinder the performance (as in the European sample), or, the presence of expatriates may be a reflection of past poor performance of the affiliate. The relationships seem to be much more complex than those originally hypothesized in this paper and by previous writers. It seems likely that the relationship between strategy configuration variables such as global integration and local responsiveness, demographic variables such as the age and size of the affiliate, and the parent company's experience overseas are partially moderated by the presence of expatriates. Unfortunately, we did not collect the detailed data on the roles played by the expatriates in our sample of affiliates necessary to explore these relationships further. This should be an avenue for further study.

Our data also seem to indicate that Japanese MNCS currently rely on Japanese expatriates to fulfill the transnational role of global integration It is possible that Japanese firms are actually underperforming relative to their competitive potential since it is quite possible that local managers, if properly trained, could perform these roles even more effectively than their Japanese counterparts. We do not have hard data to support this proposition but in a number of interviews with local executives working for Japanese affiliates in the U.S. and Europe respondents pointed out missed market opportunities caused by both a lack of awareness on the part of the Japanese that the opportunities existed and managers' inability to mobilize necessary corporate resources to take advantage of these opportunities. Future studies should examine the roles of managers, local and expatriate, in greater detail than we have been able to do in this study.

\section{Conclusions}

The results from out research indicate a general support for the propositions regarding the benefits of a transnational strategy. High integration and high local responsiveness are positively associated with performance of Japanese overseas affiliates. However, the critical issue is how to implement the transnational organizational strategy, in particular, how to quickly 
develop the appropriate human resource infrastructure to support the simultaneous integration and differentiation of the firm (Lawrence and Lorsch, 1967).

As Japanese MNCs continue to expand their operations overseas, so too will the need for greater global coordination and integration. At this point in their histories, most Japanese MNCs rely on Japanese expatriates to serve as the glue to link their far-flung operations together. As Japanese MNCs increase in size, this will lead to an increase in the demand for expatriates. Therefore, contrary to earlier predictions by a number of authors that expatriates would decrease as Japanese MNCs gained more experience overseas, the relative number of Japanese expatriates stationed in overseas affiliates is actually increasing, rather than decreasing, as expatriates are currently indispensable in their integration role. Most local managers still do not have the necessary capabilities (language, experience, knowledge of global operations, interpersonal relationships) that would allow them to perform effectively in this capacity. However, the danger for the Japanese is that there may be a logical limit to the feasibility of human resource "exports" in terms of supply, cost, and local resistance.

The answer is not in management localization, as a number of authors have maintained. It is today quite obvious that aggressive localization strategies pushed forward during the 1980s by many U.S. multinationals created groupings of fragmented "pygmy kingdoms" (in the words of one non-U.S. international executive), rather than well-coordinated global networks of interdependent units. The challenge confronting the Japanese, and all other multinationals, is how to increase the supply of managers in the transnational cadre by providing opportunities for local executives to develop the capabilities that will enable them to perform effectively in the emerging transnational integration role.

It may be that, because of their culture, language, and internal labor market traditions, the task facing Japanese MNCs may be more difficult than that for multinational companies from other countries (Yoshino, 1976). However, as our study has shown, developing transnational organizational capability is not just a matter of being a "good local citizen." It is a business imperative that will influence the very survival of MNCs into the twenty-first century. 


\section{REFERENCES}

Adler, N. and F. Ghadar. (1989). 'Globalization and human resource management'. In A. Rugman (ed.), Research in global strategic management: A Canadian perspective. JAI Press, Greenwich, CT.

Aldrich, H.(1976). 'Resource dependence and inter-organizational relations', Administration and Society, 7, pp.419-454.

Amako, T. (1991). 'The development of Japanese multinationals as European insiders and European managers' job satisfaction'. In M. Trevor (ed.), International business and the management of change: Euro-Asian perspectives. Averbury Press, Aldershot, U.K.

Baliga, B. and A. Jaeger. (1984). 'Multinational corporations: control systems and delegation issues', Journal of International Business Studies, 15, pp.25-40.

Bartlett, C, and S. Ghoshal. (1987). 'Managing across borders: New organizational responses', Sloan Management Review, 29, pp.43-53.

. (1988). 'Organizing for worldwide effectiveness: The transnational solution', California Management Review, 31, pp. 1-21.

. (1989). Managing across borders: The transnational solution. Harvard Business

School Press, Boston, MA.

Bartlett, C. and H. Yoshihara. (1988).'New challenges for Japanese multinationals: Is organizational adaptation their Achilles heel?', Human Resource Management, 27, pp.19-43.

Beechler, S. (1992). Intemational management control in multinational corporations: The case of Japanese consumer electronics firms in Asia', OECD Economic Journal: November, pp. 20-31.

Bob, D. and SRI International. (1990). Japanese companies in American Communities. The Japan Society, New York.

Boyacigiller, N. (1990?). 'Staffing in a foreign land: A multi-level study of Japanese multinationals with operations in the United States'. Paper presented at the Annual Academy of Management Conference.

. (1990b). 'The role of expatriates in the management of interdependence, complexity, and risk in multinational corporations', Journal of International Business Studies, 21, pp. 357-382. Cusumano, M. (1988). 'Manufacturing innovation: Lessons from the Japanese auto industry', Sloan Management Review, 30, pp.29-39.

Dess, G. and R. Robinson. (1984). 'Measuring organizational performance in the absence of objective measures: The case of the privately-held firm and conglomerate business unit', Strategic Management Journal, 5, pp.265-73.

Dowling, P. and R. Schuler. (1990). International dimensions of human resource management. PWS-Kent, Boston, MA. 
Ebrahimpour, M. and J. B. Cullen. (1993). 'Quality management in Japanese and American firms operating in the United States: A comparative study of styles and motivational beliefs', Management International Review, 33, pp.44-58.

Edstrom, A. and J. Galbraith.( 1977). 'Transfer of managers as a coordination and control strategy in multinational organizations', Administrative Science Quarterly, 22, pp.248-263.

Franko, L. (1973). 'Who manages multinational enterprises?', Columbia Journal of World Business, 8, pp.30-42.

Geringer, J. and L. Hebert. (1991). 'Measuring performance of international joint ventures', Journal of International Business Studies, 22, pp.249-64.

Govindarajan, V.J. and A. Gupta. (1985). 'Linking control systems to business unit strategy: Impact on performance,' Accounting, Organizations and Society, 10, pp.51-66.

. (1991). 'Knowledge flows and the structure of control within multinational corporations', Academy of Management Review, 16, pp. 768-792.

Hayes, R.H. (1981). 'Why Japanese factories work', Harvard Business Review, 59, pp.57-66.

Ichimura, S. (1981). 'Japanese firms in Asia', Japanese Economic Studies, 10, pp.31-52.

Itami, H. (1994). 'The globalization of Japanese firms', In N. Campbell and F. Burton (eds.), Japanese multinationals: Strategies and management in the global kaisha. Routledge, London.

Kobayashi, N. (1985). 'The patterns of management style developing in Japanese multinationals in the 1980s', In Takamiya, S. and K. Thurley (eds.), Japan's emerging multinationals: An international comparison of policies and practices. University of Tokyo Press, Tokyo.

Kopp, R. (1994). 'International human resource policies and practices in Japanese, European, and United States multinationals', Human Resource Management, 33, pp.581-599.

Maljers, F. (1992). 'Inside Unilever: The evolving transnational company', Harvard Business Review, September-October, pp.46-53.

Milliman, J., M. Von Glinow and M. Nathan. (1991). 'Organizational life cycles and strategic international human resource management in multinational companies: Implications for congruence theory', Academy of Management Review, 16, pp.318-339.

Negandhi, A. (1979). Quest for survival and growth: A comparative study of American, European and Japanese multinationals. Praeger, New York.

Negandhi, A. and B. Baliga. (1981). Tables are turning: German and Japanese multinational companies in the United States. Oelgeschlager, Gunn \& Hain Publishers, Cambridge, MA.

Ouchi, W. (1981). Theory Z. Addison-Wesley, Reading, MA.

Perlmutter, H. (1969). 'The tortuous evolution of the multinational corporation', Columbia Journal of World Business, January-February, pp.9-18. 
Perlmutter, H. and D. Heenan. (1979). Multinational organization development. Addison-Wesley, Reading, MA.

Pfeffer, J. and G. Salancik. (1978). The external control of organisations: A resource dependence perspective. Harper and Row, New York.

Porter, M. (1986). Competitive advantage. Free Press, New York.

Pucik, V. (1994). 'The challenges of globalization: The strategic role of local managers in Japanese-owned US subsidiaries', In N. Campbell and F. Burton (eds.), Japanese multinationals: Strategies and management in the global kaisha. Routledge, London.

Rosenzweig, P. (1994). 'The new 'American challenge': Foreign multinationals in the United States', California Management Review, Spring, pp.107-123.

Rosenzweig, P. and J. Singh. (1991). 'Organizational environments and the multinational enterprise', Academy of Management Review, 16, pp.340-361.

Sako, M. (1994). 'Training, productivity, and quality control in Japanese multinational companies'. In M. Aoki and R. Dore (eds.), The Japanese firm. Claredon Press, Oxford.

Stening, B. and J. Everett. (1984). 'Japanese managers in Southeast Asia: Amiable superstars of arrogant upstarts?', Asia Pacific Journal of Management, 1, pp.171-179.

Tachiki, D. (1991). 'Japanese management going transnational', Journal for Quality and Participation, 14, pp.96-107.

Taylor, W. (1991). 'The logic of global business: An interview with ABB Percy Barnevik', Harvard Business Review, 69, pp.90-105

Thompson, J.(1967). Organizations in action. McGraw-Hill, Chicago.

Trevor, M. (1983). Japan's reluctant multinationals: Japanese management at home and abroad. St. Martin's Press, New York.

Tung, R. (1982).'Selection and training procedures of U.S., European, and Japanese multinationals', California Management Review, 25.

Wakabayashi, M. and G. Graen. (1991). 'Cross-cultural human resource development: Japanese manufacturing firms in central Japan and central US states'. In M. Trevor (ed.), International business and the management of change: Euro-Asian perspectives. Avebury Press, Aldershot, U. K.

Yoshino, M. (1976). Japan's multinational enterprises. Harvard University Press, Cambridge, MA.

Zeira, Y. (1976). 'Management development in ethnocentric multinational corporations', California Management Review, Summer, pp.34-41. 
Zeira, Y., E. Harari and D. Nundi. (1975). 'Some structural and cultural factors in ethnocentric multinational corporations and employee morale', The Journal of Management Studies. February, pp.66-82. 